\title{
"ENDOCROWN": A Reliable Alternative to Restorate RCT Molar! - Two Case Reports
}

\author{
Debbabi Imen*, Nouira Zohra, Saafi Jilani, Harzallah Belhassen and Cherif Mounir \\ Department of Fixed Prosthodontics, Dental Clinic of Monastir, Tunisia
}

Submission: August 25, 2018; Published: September 24, 2018

*Corresponding author: Debbabi Imen, Department of Fixed Prosthodontics, Faculty of dental medicine, Dental Clinic of Monastir, Tunisia; Tel: +21627430478; Email: Debbabiimen@yahoo.fr

\begin{abstract}
Restoration of extensively damaged endodontically treated molars is a daily challenge for the practitioner. Although the classical post crown remains widely spread in dentistry, its invasiveness has been largely criticized. New materials and therapeutic options based entirely on adhesion are nowadays available.

The concept of endocrown was described in 1999 by Bindl and Mormann to limit the use of root anchorages. With the progression of adhesive techniques and CAD/CAM (computer aided design computer aided manufacturing), endocrown seems to be an alternative therapeutic to the restoration of devitalized molars. It's simple and efficient concept is more compatible with the philosophy of bio integrate prostheses, and this type of reconstruction, which is still uncommon, should be more widely known and used in restorative dentistry.
\end{abstract}

Keywords: Endocrown; Endodontically treated tooth; Badly mutilated teeth; Biomimetic reconstruction

\section{Introduction}

The restoration of the endodontically treated teeth is a topic widely debated in the literature and this for many years $[1,2]$. It is currently accepted that the amount of residual tissue is probably the most important predictor of clinical success. The best solution is therefore to adopt a method as economical as possible. Many adhesive techniques that do not require root anchoring are currently indicated to restore the depilated tooth. They constitute as many reliable alternatives to the prosthetic crown [3]. Endocrowns are a viable option for the restoration of extensively damaged endodontically treated posterior teeth. The main objective is to achieve a bonded biomimetic reconstruction, i.e., minimally invasive of root canals [4]. This article highlights two different case reports of badly mutilated endodontically treated teeth, effectively managed by means of endocrowntype restorations. The first case of an endocrown presented is a mandibular first molar (\#46) and the second case presented is a maxillary first molar (\#26).

\section{Case Reports}

\section{Case report 1}

A 20-year-old healthy female consulted the department of fixed prosthodontics at the dental clinic of Monastir (Tunisia) to restore her extensively damaged mandibular first right molar (\#46). The patient asked to make an aesthetic prosthesis that does not require a long period of treatment. The clinical examination revealed that the tooth is restored with glass ionomer cement. The tooth is asymptomatic. Radiological examination revealed that it is well endodontically treated. The pulp chamber is wide and deep (Figure 1). The residual tooth walls are supragingival. After curettage of the coronary filling, the quality of the remaining dental tissues was checked again. The analysis of the anatomy of the tooth is fundamental to the indication of any preparation [5].

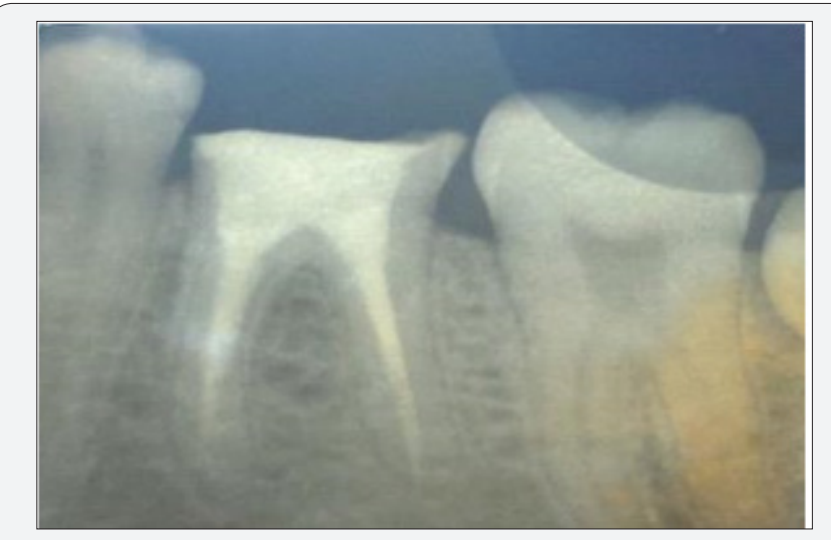

Figure 1: Periapical X-ray.

Prosthetic decision: Owing to its conservative aspect and excellent esthetic result, the decision to perform lithium disilicate 


\section{Advances in Dentistry \& Oral Health}

endocrown by CAD/CAM system to restorate the mandibular molar was taken with the patient's consent.

Tooth preparation: Prior to tooth preparation, shade was selected using VITA master shade guide considering neighboring and opposite teeth. The key areas of the restoration are the cervical sidewalk and the cameral cavity (Figure 2) [6]. During preparation, the root canals were not shaped and were not invested [7]. They were, therefore, not weakened by drilling and did not have to undergo the effect of constraints, as when setting up an anchorage [8] (Figure 3).

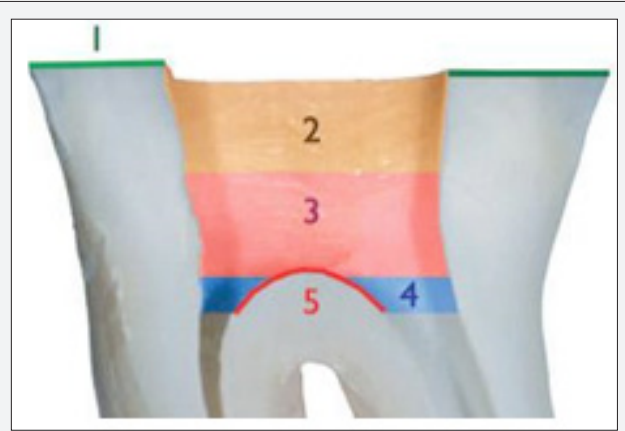

Figure 2: Key areas for endocrown design; 1- the cervical sidewalk,2- the endodontic access cavity, 3-the pulp chamber, 4-the root canal inlet, 5-the saddle-shaped pulpal floor; parts 2, 3,4 constitute the cameral cavity.

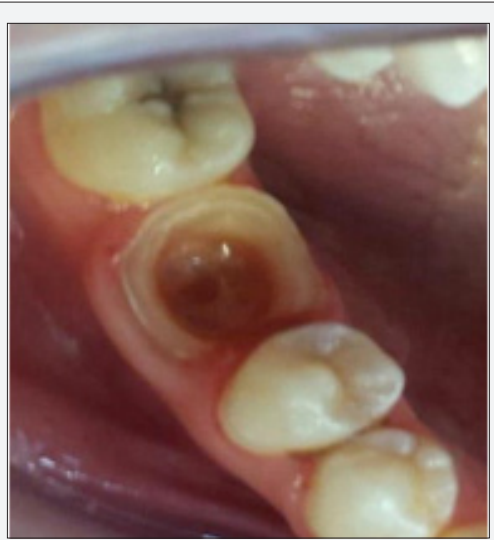

Figure 3: \# 46 was prepared to receive an endocrown.

Instrumentation and reduction values: The preparation of the cervical sidewalk was made using a diamond dental bur "wheel" (green ring) (818040C-FG). The shape of the dental bur ensures the creation of a flat surface. The reduction must be at least $2 \mathrm{~mm}$ at the support cusps and guide cusps, to allow enough space for the ceramic. The position of the cervical sidewalk determined the volume left to the ceramics [6].

The cameral cavity was prepared using a cylindrical-conical dental bur (green ring) (848 018F-FG). The taper of the dental bur is $3.5^{\circ}$ to allow an overall stump equal to $7^{\circ}$. These values were identical to those described by Jorgensen as a minimum stump which promotes retention and stabilization [9]. These were the minimum stump values for intraoral point-and-click imaging with a Cerec type camera [10].
Impression procedure: A one-phase impression, after retraction cords placement, was taken with putty and light body polyvinyl siloxane material and sent to the laboratory (Figure 4).

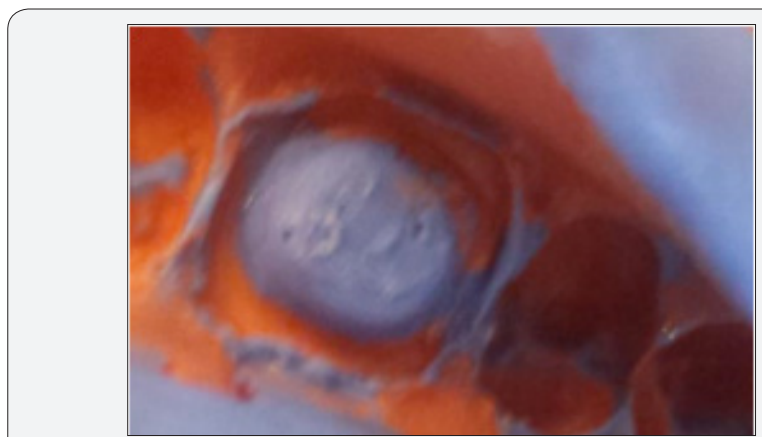

Figure 4: Impression.

Temporization: In the current case study, temporization during interappointment period was done with an interim prosthesis made with self-curing resin (Figure 5). The cementation was made using a temporary cement without eugenol (Temp Bond NETM).

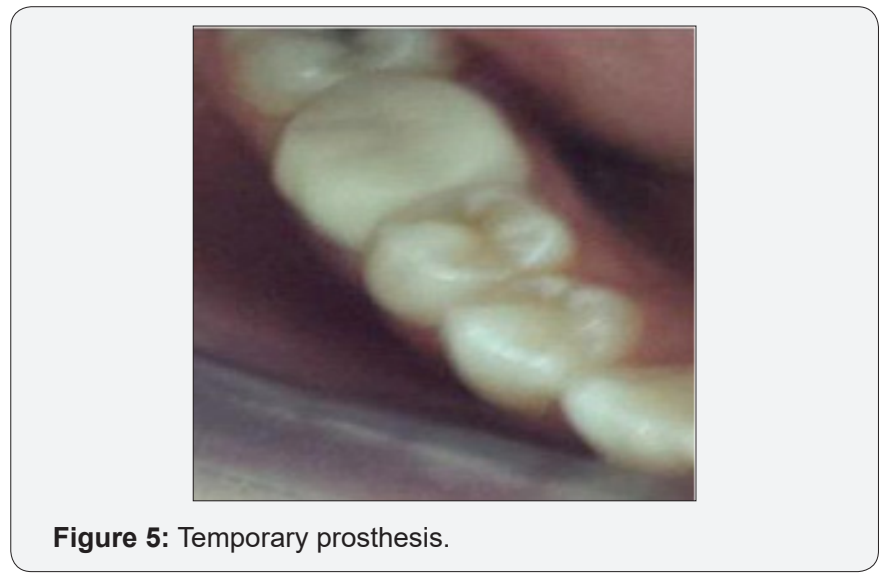

Material selection: The lithium disilicate ceramic (IPS e.max CAD) was selected thanks to its optical and mechanical properties and its high biocompatibility which offer us a promising esthetic result. Once the working impression is validated, the dental laboratory processed endocrown by CAD/CAM system. The prosthetic project was machined (CAM: computer-aided manufacturing) in a ceramic block of lithium disilicate (Figure 6).

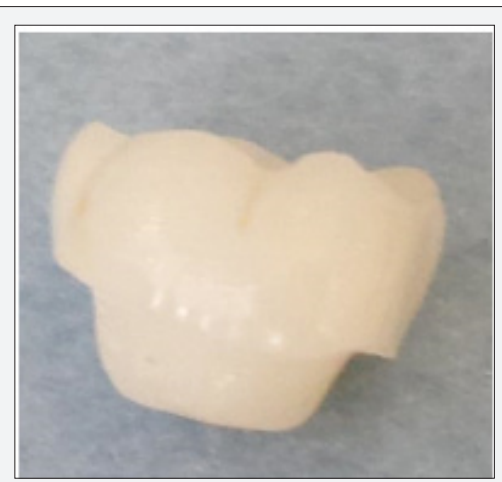

Figure 6: Endocrown fabricated by CAD/CAM system. 
Try in protocol: Removal of the provisional restorations was straight forward. Tooth surfaces were thoroughly cleaned. Endocrown was tried in a bisque state. All these parameters were checked: precise marginal fit, correct length and mesio-distal dimension, adequate contour in harmony with the surrounding tissues, color mimicry to natural adjacent teeth and proper esthetics. Aspects such as contact points and occlusion were, also, assessed and adjusted. The adhesive cementation was programmed in the following appointment after staining and glazing.

Bonding procedure: The final prosthesis is bonded using a self-adhesive composite cement (RelyX ${ }^{\mathrm{TM}}$ Unicem, 3M ESPE). Extreme care was taken during the bonding protocol. The following sequenced steps were meticulously considered. After Bonding procedure, static and dynamic occlusion were scrutinized.

Recall checks: Regular recalls were programmed during which oral hygiene maintenance and gingival margins stability were evaluated. The patient was satisfied with both esthetic and functional outcome.

\section{Case report 2}
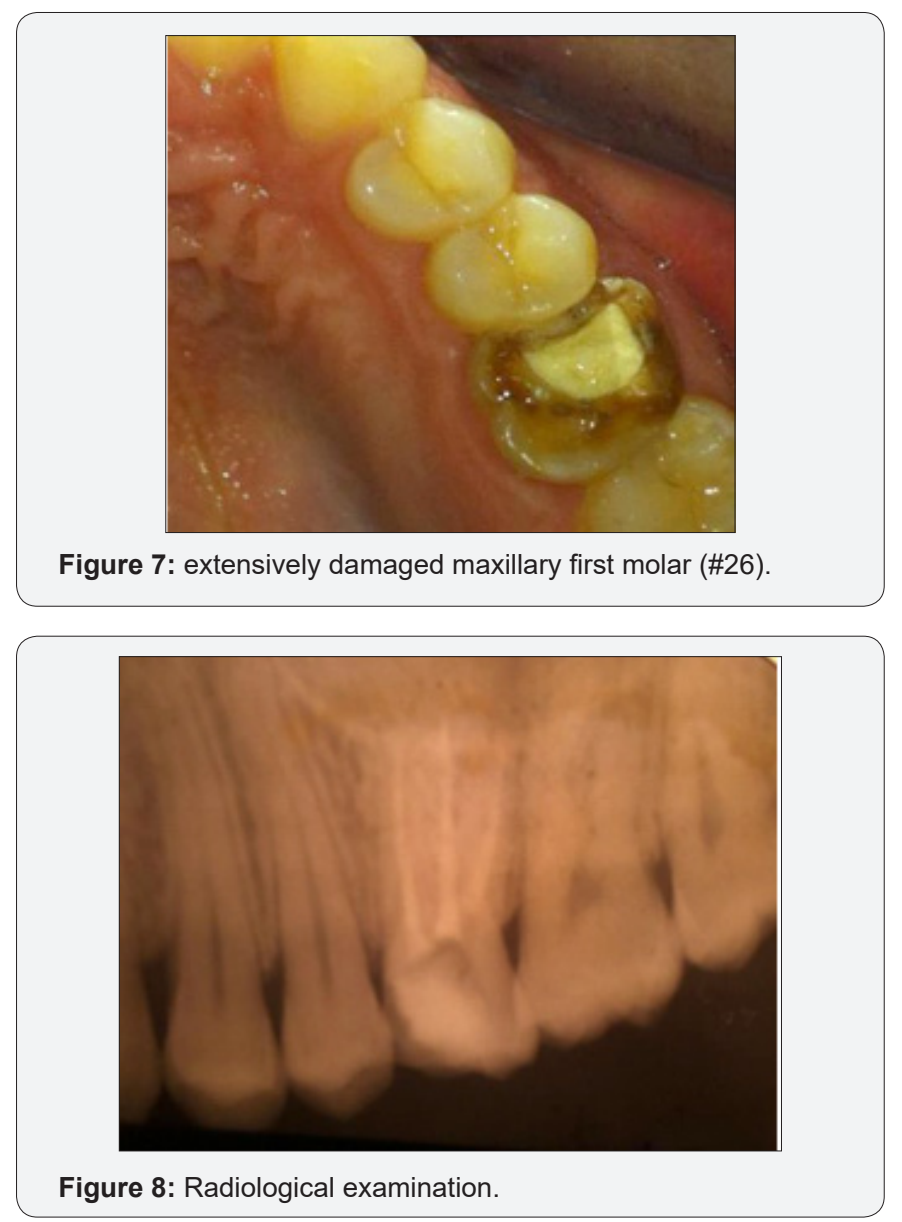

A 24-year-old healthy female consulted the department of fixed prosthodontics at the dental clinic of Monastir to restore her damaged maxillary first molar (\#26). The clinical examination revealed that his tooth was filled by temporary filling material.
The tooth presented a decayed, softened and brittle tissue with a dilapidated mesial dental wall which seems supragingival (Figure 7). Radiological examination revealed that the tooth was endodontically treated (Figure 8). Temporary filling material was deposited and then the softened and brittle tissue was cured. The dental walls revealed different heights after preparation. It is juxta gingival at the mesial and supragingival at the level of remaining coronal contour. The pupil cavity is wide and deep (Figure 9).

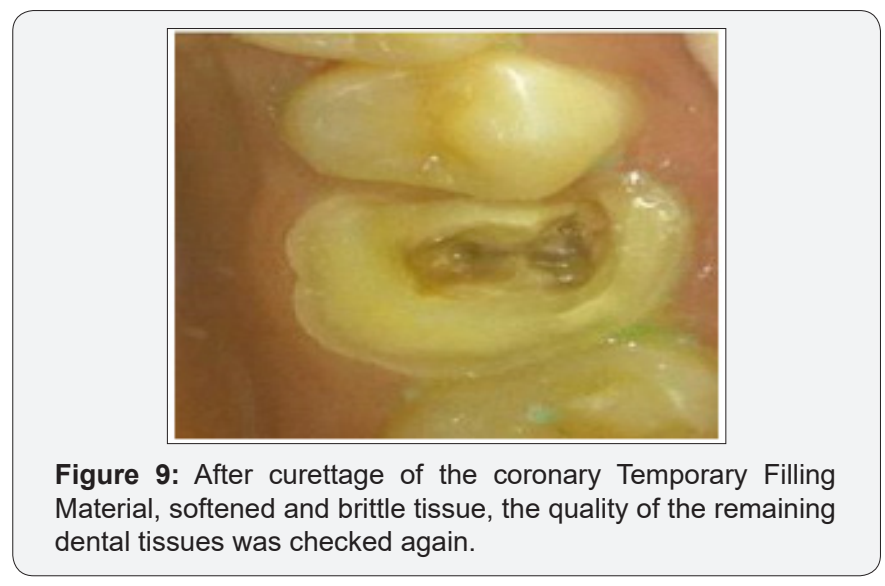

\section{Prosthetic decision}

The decision to perform lithium disilicate endocrown to restorate the maxillary first molar was taken with the patient's consent. We opted for lithium disilicate ceramic (IPS e. max CAD) for its optical and mechanical properties and its high biocompatibility which would offer us promising esthetic results. Once the working impression was validated, the dental laboratory processed Endocrown by CAD/CAM system.

\section{Teeth preparation}

Prior to tooth preparation, shade was selected using VITA master shade guide considering neighboring and opposite teeth. The cervical sidewalk has a width of at least $2 \mathrm{~mm}$ over a minimum of $60 \%$ of the circumference. The mesial proximal carious lesion forced us to achieve a juxta gingival limit at the level of the lesion. The difference in level between the different zones is corrected by a slope of $60^{\circ}[6]$.

\section{Impression procedure}

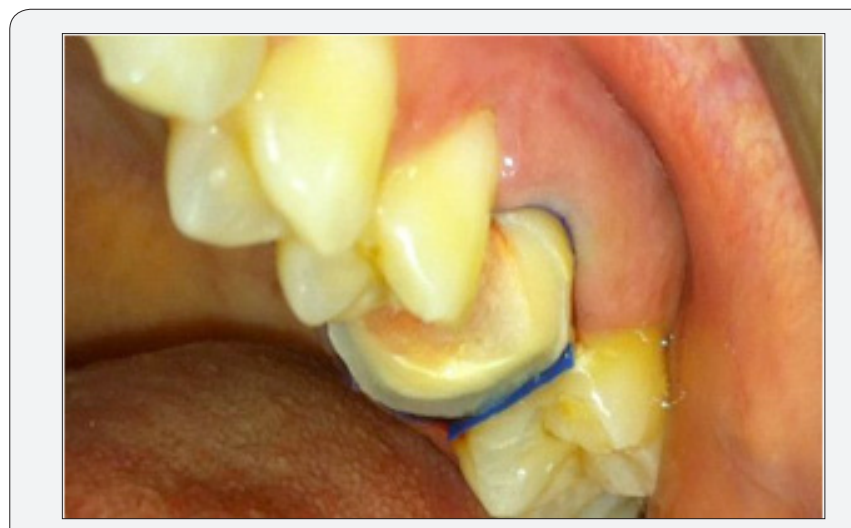

Figure 10: retraction cords and interdental strip placement. 
After retraction cords and interdental strip placement to highlight the finish line of the tooth (Figure 10), a one-phase impression was taken with putty and light body polyvinyl siloxane material and sent to the laboratory.

\section{Temporization}

Temporization was done with a temporary prosthesis made with self-curing resin. Cementation was performed using a temporary free eugenol cement (Temp Bond NE TN). The provisional coronal restoration is often intended for diagnostic and therapeutic purposes, being a test structure where all the necessary functional, occlusal, and esthetic adjustments can be carried out to optimize incorporation of the definitive prosthesis.

\section{Try in protocol}

The endocrown was tried in mouth (in a biscuit bake state) after removing of the provisional restoration. The marginal fit, shade, shape and occlusion were evaluated. The static occlusion was controlled to check the bilateral distribution of the contacts at Maximum Intercuspation. Dynamic occlusion was controlled to ensure the absence of interferences.

\section{Bonding procedure}

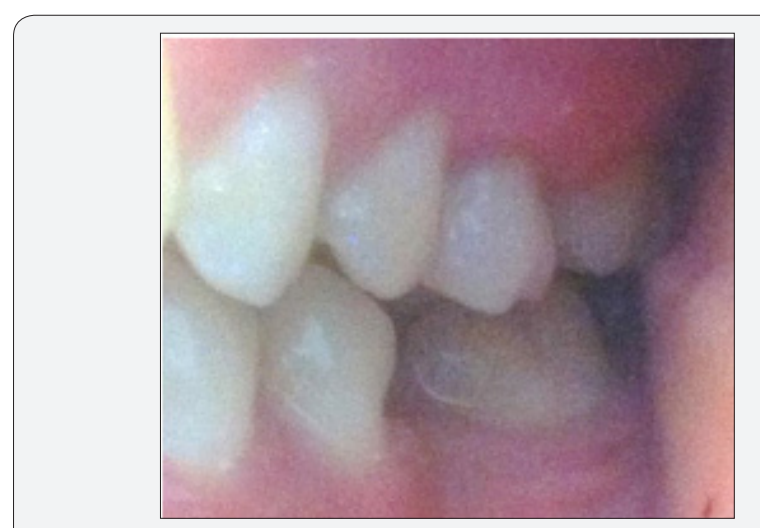

Figure 11: Final result (lateral view of the endocrown).

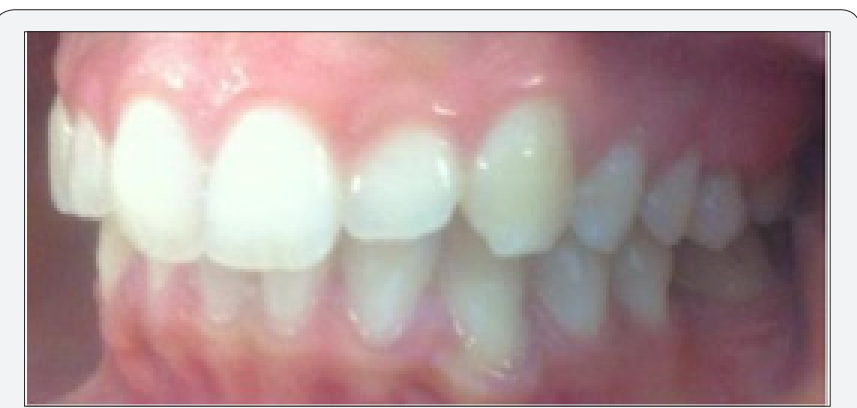

Figure 12: The static occlusion.

After glazing the ceramic, the final prosthesis is bonded using the MetaCem Kit (Figure 11). Static and dynamic occlusion were, then, scrutinized (Figure 12 \& 13). Minor adjustments were realized by means of fine diamond bur. Finally, the bonded endocrown was finished and polished. The patient was satisfied with both esthetic and functional outcome.

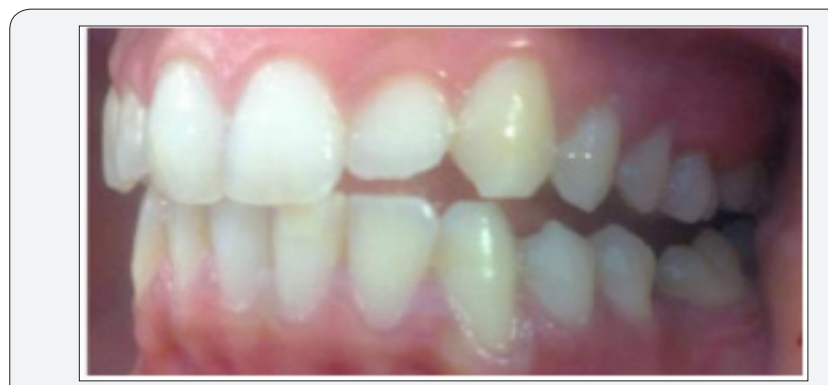

Figure 13: Dynamic occlusion

\section{Recall checks}

Regular recalls were programmed during which oral hygiene maintenance and gingival margins stability were evaluated.

\section{Discussion}

The most commonly recommended treatment option for such cases associated with significant loss of two or more dentin walls is the placement of conventional post and core followed by a crown $[4,11]$. However, there is a need for a definite core filling, particularly in cases of posterior teeth where the masticatory forces are directed parallel to the long axis of the tooth. This is since the use of intraarticular posts alone might not contribute to an increased retention of the restoration, as stated in various studies [12]. In addition, post possesses several disadvantages [13]. Though Pissis [14] was the forerunner of the endocrown technique. It was first described as an adhesive total porcelain endodontic crown that can be fixed to a root canal treated posterior tooth by Bindl et al. [15]. Some authors [16] consider that the essential parameter for the indication of this technique, is the depth of the cameral cavity, which must have a minimum depth of 4 to $5 \mathrm{~mm}$. The cameral anchorage must be exploited to the maximum without going to prepare, and thus to weaken, the rest of the roots [17]. The "sidewalk" determines the cervical limit of the preparation. It is preferentially supragingival, even juxta gingival [6].

Endocrown is a prime indication in cases of molars with obliterated, short, dilacerated or fragile roots and when limited interocclusal space exists with the opposing dentition. Besides, it is indicated in cases where there are minimally subjected functional and lateral stresses on the tooth [18]. However, endocrown is contraindicated in the following cases:

1. Where the pulp chamber depth is less than $3 \mathrm{~mm}$ or cervical margin is less than $2 \mathrm{~mm}$ wide,

2. if adhesion cannot be assured, and

3. presence of only negligible remaining tooth structure [4].

Once the tooth has been endodontically treated, the external and internal peripheral preparations are carried out. "Butt margin" type preparations, in direct affixing to dental tissues without persistence of external walls are described [18]. With this 
type of limit ("butt margin") the notion of strapping is completely non-existent [3].

The pulp chamber has a specific anatomy in the mandible and maxilla molar. Its shape, trapezoidal in the mandibular molars and triangular in the maxillary molars [12] ensures the anti-rotational blockage of the restoration. Indeed, this morphology will allow to fight against micromovements initiated during the masticatory phases which may cause the phenomenon of breaking the mode of joining and thus loosening [3]. Gutta-percha is removed at a minimal depth of not more than $2 \mathrm{~mm}$ at the canal entrances to optimize the saddle anatomy of the floor. His anatomy in "saddle" allows the calibration of the restoration [6].

Different materials can be used to fabricate an endocrown such as feldspathic and glass-ceramics, hybrid composite resin and the newest computer aided design/ computer aided manufacturing (CAD/CAM) ceramic and composite resin blocks.

The authors prefer micro-hybrid composite resins-lab-made or in the form of CAD/CAM blocks-due to their stress-absorbing properties and their practical benefits like the possibility to modify and repair the surface easily. Reinforced glass-ceramics (e.g. IPS e.max Press and CAD, Ivoclar, may be alternatives to this concept [19]. Vitro ceramic has proven properties of biocompatibility with the gum; it is, moreover, mimetic. The coefficient of wear of a glass ceramic is identical to that of the natural tooth, thus allowing harmonious relations with natural antagonistic teeth [6]. It is usually fabricated by using computer-aided milling techniques (computer-aided design/manufacturing) or by molding ceramic materials under pressure [4].

Finally, the junction mode in this type of reconstruction must always have an adhesive component. It therefore seems preferable to use materials containing the molecule MDP (10-methacryloyloxy-decyl-dihydrogenphosphate) (ex: Panavia ${ }^{\circledR}$, Kuraray Medical) or resins 4 META (4-methacryloxyethyltrimellitat-anhydrid) (ex: Super-Bond C \& B®, Sun Medical) or self-adhesive composite cements (eg RelyX ${ }^{\mathrm{TM}}$ Unicem, 3M ESPE) [3].

The success and longevity of endocrowns also depend upon various other factors, such as operator skill, appropriate preparation techniques, adequate selection of most suitable ceramic options, and the choice of bonding material. In certain situations, endocrown has been rejected as a treatment option because of the lack of adhesive bonding and patients' economical constraint, as the main criteria [4].

\section{Pronostic}

Indeed, different case reports highlighted the interest of this technique to restore the aesthetics and function of molars [20]. The study by Bindl et al. showed that the endocrown survival rate $(87.1 \%)$ does not differ significantly from that of peripheral crowns (94.6\%) at 60 months. These results, however, are valid only for molars which offer a large bonding surface, while premolars show poorer results $(68.8 \%$ and $97.0 \%$ respectively for endocrowns and peripheral crowns) on the same date [3,21]. A study related to 20 RCT and reconstituted molars by "endocrown" performed in CAD / CAM technique conducted by Bernhart et al, showed a success rate of $90 \%$ at two years, success evaluated, again, according to the USPHS criteria. The two failures were fractures of the prosthetic crowns $[3,22]$.

\section{Conclusion}

Endocrown is a reliable alternative to restorate a non-vital root canal treated molar. It consists of a circular butt-joint margin and central retention cavity inside pulp chamber. The goal is to achieve minimally invasive preparations and to protect existing tooth structure. The evolution of ceramic technology especially Dental CAD/CAM systems and adhesive cementations have increased opinions to produce single all ceramic endocrowns with high biocompatibility and optimal mechanical properties. In addition, it's easier technique, less clinical time, and better acceptance make it a superior option among the various treatment alternatives.

\section{References}

1. Goto Y, Ceyhan J, Chu SJ (2009) Restorations of endodontically treated teeth: new concepts, materials, and aesthetics. Pract Proced Aesthet Dent 21(2): 81-89.

2. Ree M, Schwartz RS (2010) The endo-restorative interface: current concepts. Dent Clin North Am 54(2): 345-374.

3. D'Incau E, Bartala M, Dos-Santos A (2011) Traitement de la dent dépulpée postérieure. La stratégie de la préservation. Réalités Cliniques 22(1): 273-280.

4. Selvanathan MJV, Saravanakarthikeyan B, Sekar M (2017) "ENDOCROWN" An Effective viable Esthetic Option for Expurgated Endodontically treated Teeth: Two Case Reports. Journal of Operative Dentistry and Endodontics 2(2): 97-102.

5. Donovan TE, Chee WW (1993) Endodontically treated teeth: a summary of restorative concerns. J Calif Dent Assoc 21(12): 49-56.

6. Fages M, Bennasar B, Raynal J, Margerit J (2011) Endocouronne: les critères de réussite. Les cahiers de prothèse p. 155.

7. Clark D, Khademi JA (2010) Case studies in modern molar endodontic access and directed dentin conservation. Dent Clin North Am 54(2): 275-289.

8. Fernandes AS, Dessai GS (2001) Factors affecting the fracture resistance of post-core reconstructed teeth: a review. Int J Prosthodont 14(4): 355-363.

9. Schilinburg HT, Hobo S, Whitsett LD, Jacobi R, Brackett SE (1997) Fundamentals of fixed prosthodontics. Quintessence Books, Chicago, USA.

10. Fages M, Bennasar B, Raynal J, Landwerlin O, Margerit J (2011) L'empreinte optique intra-buccale en pratique quotidienne. Stratégie Prothétique 11(2): 107-119.

11. Akkayan B, Gülmez T (2002) Resistance to fracture of endodontically treated teeth restored with different post systems. J Prosthet Dent 87(4): 431-437.

12. Schwartz RS, Robbins JW (2004) Post placement and restoration of endodontically treated teeth: a literature review. J Endod 30(5): 289301.

13. Ma PS, Nicholls JI, Junge T, Philips KM (2009) Load fatigue of teeth with different ferrule lengths, restored with fiber posts, composite resin cores, and all-ceramic crowns. J Prosthet Dent 102(4): 229-234. 
14. Trope M, Maltz DO, Tronstad L (1985) Resistance to fracture of restored endodontically treated teeth. Available from: Dent Traumatol 1(3): 108-111.

15. Pissis P (1995) Fabrication of a metal-free ceramic restoration utilizing the monoblock technique. Pract Periodontics Aesthet Dent 7(5): 83-94.

16. Bindl A, Richter B, Mörmann WH (2005) Survival of ceramic computeraided design/manufacturing crowns bonded to preparations with reduced macro retention geometry. Int J Prosthodont 18(3): 219-224.

17. Lin CL, Chang YH, Chang CY, Pai CA, Huang SF (2010) Finite element and Weibull analyses to estimate failure risks in the ceramic endocrown and classical crown for endodontically treated maxillary premolar. Eur J Oral Sci 118(1): 87-93.

18. D'incau E, Soenen A, Pia JP (2014) Restaurer sans tenon et sans couronne les dents postérieures? Le Fil Dentaire 98.
19. Siqueira JF (2001) Aetiology of root canal treatment failure: why welltreated teeth can fail. Int Endod J 34(1): 1-10.

20. Rocca GT, Bonnafous F, Rizcalla N, Krejci I (2010) A technique to improve the esthetic aspects of CAD/CAM composite resin restorations. J Prosthet Dent 104(4): 273-275.

21. Lander E, Dietschi D (2008) Endocrowns: a clinical report. Quintessence Int 39(2): 99-106.

22. Bernhart J, Brauning A, Altenburger MJ, Wrbas KT (2010) Cerec 3D endocrowns-two-year clinical examination of CAD/CAM crowns for restoring endodontically treated molars. Int J Comput Dent 13(2): 141154.

\section{Your next submission with Juniper Publishers will reach you the below assets}

- Quality Editorial service

- Swift Peer Review

- Reprints availability

- E-prints Service

- Manuscript Podcast for convenient understanding

- Global attainment for your research

- Manuscript accessibility in different formats

( Pdf, E-pub, Full Text, Audio)

- Unceasing customer service

Track the below URL for one-step submission https://juniperpublishers.com/online-submission.php 